\title{
Aging as a Social Problem in Asia: A Sociological Assessment
}

\author{
Mohammad Taghi Sheykhi* \\ Department of Social Science, Alzahra University, Iran
}

*Corresponding author: Mohammad Taghi Sheykhi, Professor of Sociology, Department of Social Science, Alzahra University, Tehran, Iran

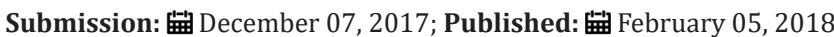

\begin{abstract}
The paper explores how change in demographic structure in Asia since 2000 has enhanced population aging- a phenomenon contributing to a variety of social problems in different Asian societies. Increasing median age has created a better chance of higher life expectancies leading to population aging in general. But, many Asian countries do not know how to cope with the phenomenon. Yet, and in increasing cases major institutions of societygovernments, economies, and the families loosely respond to the aging of a large number of individuals. In this way, various social problems including caring, nursing, pensions, homeliness, medication and so on are left with such aging population. As human beings, and the process of aging, we need to devise many policies and practices to take into account to predictably occur in later years such as retirement pensions, medical interventions, social security etc. to help the aging population in various occasions. While the phenomenon is well subtle, it is not easily observed.
\end{abstract}

Keywords: Population aging; Asian societies; Social problems; Median age; Life expectancy

\section{Introduction}

In the present paper, the author tries to explore and reflect the phenomenon of aging comparatively in Asia. While the world is aging at an unprecedented pace, the outcomes are not the same in all regions. However, while it took Europe to double the proportion of its elderly population from 7 to 14 percent almost within a century, the same change is appearing in Asian countries such as Japan, South Korea, Singapore, Iran and the like in shorter span of time. Overall, population aging being one of the major achievements of the 20th century, it needs appropriate sociological assessment. Aging in Asian settings, has in recent decades become an important topic of discussion at many colloquiums at national and international levels. While aging is an issue of high priority within many Western societies, different aspects of the phenomenon is yet to find its importance in many parts of Asia as well. The extreme population aging in the West as well as in many parts of Asia has led, and is yet leading to increase the demand for further social and health services etc. Issues stemming from family relations, health services, retirement, and economic well-being of the aging population are sociologically appraised in the present article. Agerelated topics are studied and the demographic profiles highlight the relevant issues of the phenomenon. The scenario leads to new challenges particularly in Asia where the history of aging is not too old. We will see how aging affects the quality of life in all areas. Asia, with a larger population, and larger young population structure, will experience aging even faster than the West. While aging is in process in Asia, "elderly aging" or aging beyond hundred years or so, is in process in the West. However, per capita income, elderly's rate of literacy, financial resources of the elderly etc. all affect the quality of life of the aging population too.

Age, being a characteristic that every society uses to move people into and out of statuses, roles, rights and obligations, is reflected differently in various societies. The process of creating social categories based on age is known as age grading and aging, and varies from culture to culture and from one historical period to another. We will see as to how changes in proportion of people in a population at each age level have important social consequences in different societies. One of our objectives in this paper is to find out the connotation of such changes in Asia. Population aging or graying due to increased longevity, and a declining birth rate, is more prevalent in the industrial world rather than the developing world. The paper finds out how due to change in population structure, population aging will immediately change trends in the decades ahead with special reference to Asia.

Population aging as an unprecedented phenomenon in human history is increasingly observed in the developed and the developing world- leaving behind social, economic, health and other problems. Currently, increase in the proportions of the elderly (60 years and older), accompanied by declines in the proportions of the young age groups (under the age of 15), have created various problems, or are potentially responsible for challenges in different dimensions. According to projections, by the year 2050, the number of older persons in the world will exceed the number of the young for the first time in history [1]. Such a scenario will lead to new challenges 
in human life. However, by 1998, this historic reversal in relative proportions of the young and the old had already taken place in more developed regions.

The phenomenon of aging, being pervasive, is affecting each and every one of us in every society irrespective of age and sex. It has a direct bearing on the intergenerational equity and solidarity which are the very foundations of the societies. Hence, quality of life was widely affected due to this current change.

Likewise, the consequences and implications of aging are reflected in all facets of life, such as, affecting the quality of life in all areas. For example, in the economic area, population aging will have impacts on economic growth, saving, investment, consumption, labor market, pensions, taxation etc. Also, in the social sphere, aging affects health and health care, family composition, living arrangements, housing etc. All these and even more, inevitably affect various dimensions of quality of life.

However, the trend towards aging is largely irreversible in the decades to come simply as a result of demographic transition taken place in the world in which fertility and mortality both have decreased in an unprecedented manner.

According to UN estimates, the world added approximately 600 million older persons to its population at the turn of the century, i.e. almost 3 times the number it had in the mid of the $20^{\text {th }}$ century. However, by the mid of the $21^{\text {st }}$ century, the world elderly will again triple - reaching 2 billion. Such a great change in population structure needs more attention, more relevant resources, and more appropriate planning.

Though the developed regions experienced aging earlier, yet the less developed regions including Asia are following the same path. In the more developed world in particular in Western Europe, almost one- fifth of the population was estimated to be aged 60 years and older in the year 2000. By the year 2050, this proportion is projected to reach one - third. On the other hand, while only about 8 percent of the population in Asia is currently over the age of 60, this proportion will increase to 20 percent by the mid of the $21^{\text {st }}$ century. Such a dramatic change will need relevant and appropriate infrastructures to be able to handle the Asian aging population, and to be adequately responsive to the quality-of-life needs of the emerging elderly.

As the speed of population aging is much faster in Asia as compared with Europe, and the whole developed world, Asia has much more to do, to adjust with the consequences of such population aging. Likewise, population aging in Asia is taking place at much lower levels of socio-economic development than was the case in Europe in the mid of the $20^{\text {th }}$ century.

Demographically speaking, in 2000 , the median age for the world was 26 years. The country with youngest population is known as Yemen, with a median age of 15 years, and the oldest is known to be Japan, with the same indicator of 41 years. By 2050, the world median age is projected to have increased by about 10 years e.i., to 36 years. The country with the youngest population at that time is predicted to be Niger in Africa, with a median age of 20 years, and the oldest is expected to be Spain, with a median age of 55 years by that year [1]. Such a change will give a different perspective to the aging population so far as their quality of life is concerned.

A new phenomenon of the "elderly aging" is also growing, and it is estimated that those aged 80 years, are currently increasing at the rate of 3.8 percent per annum, and the number of which comprise more than one tenth of the total number of the older persons. Under such conditions, one fifth of the older persons will be 80 years and older by the mid of the $21^{\text {st }}$ century. Such a scenario indicates that the dependency burden on working-age groups (1546) will be remarkable and heavy.

While the majority of the aging population are women, more due to the fact that the female life expectancy is higher than men, as estimated in the year 2000, there were 36 million more women than men aged 60 years and above. Also, as the ratio will have more change/gap at the age of 80 and above, i.e. almost two men for every five women, more specific plans should be implemented so as to protect the quality of life of such potentially vulnerable people.

So far as the income is concerned, countries with higher per capita income tend to have lower rates of the elderly participation, and on the contrary, to a greater extent, older people participate in labor markets in the less developed regions including Asia largely due to the limited coverage of retirement schemes, and the small incomes when provided. Therefore, many have to work even at the ages not suitable and recommended for their physical conditions, which eventually leads to poor quality of life among them.

Another factor responsible for low quality of life among the elderly is known as illiteracy. Though a lot of efforts have been made to eradicate illiteracy, yet it is common especially among the Asian elderly. According to estimates, almost half of all the people 60 years and above in the less developed regions including Asia have been declared as illiterate by the year 2000 . Only about $1 / 3$ of older women and three fifths of the older men could read and write at basic level, whereas in Europe, literacy has almost approached full coverage expect in some countries.

In the study of older people in modern society, growing attention has been focused on their life- satisfaction and quality of life $[2,3]$. Life - satisfaction is related to the degree to which people feel they achieve their aspirations, morale and happiness. But, how the quality of life is measured is difficult to decide. In a nutshell, ways of measuring quality of life of the elderly people could include: their individual characteristics, their physical and mental health, their dependency, their housing, their social environment, their comforts, security etc. However, to develop a system of health care and security for the elderly, paying special attention to the needs of the women is highly recommended with a view to enhancing the ability of families to take care of the elderly people within the families in general. 


\section{Method of Research}

Methodology used in the present article is of qualitative type. In that, various paradigms for finding facts have been used. Qualitative research usually studied the people in their natural setting. In finding facts for the research, the researcher engaged in careful data collection and thoughtful analysis of what was relevant. In the documentary research applied in the present article, printed and written materials were widely regarded. The research was performed as a qualitative library type in which the researcher had to refer to relevant and related sources. In the present research, various books on aging were thoroughly investigated, and the needful inferences were made. The data fed by the investigator in the present research is dependable and reliable. Though literature on Iranian aging is very limited, yet the author has tried to investigate many foreign resources as well, in order to elicit the necessary information in order to build up the text.

\section{Old Age Crisis}

While the age of retirement is lowering in many parts of the developing world due to large number of young people waiting to get into jobs, it is in contrast increasing in the Western world especially in (EU) due to increase in the number of the aging people and lack of youth to enter into active production sector. However, the emerging problem is somehow currently being solved within many European countries by attracting guest workers from the developing countries.

Systems of financial support for old people are in trouble worldwide. To ensure that, these systems continue to protect the old, and promote economic growth, countries need to consider comprehensive pension reforms. Based on estimates, over the next 25 years, the proportion of the world's population over 60 will nearly double, i.e. from 9 percent to 16 percent. However, populations are aging much faster in developing countries than they did in industrial countries. As today's young workers near retirement around the year 2030, 80 percent of the world's old people will live in what today are developing countries (mainly Asian). More than half will live in Asia, and more than a quarter in China alone [4]. These countries need to develop their old-age systems quickly, and make them sufficiently resilient to withstand rapid demographic change. Under the conditions that the extended family system and village support networks on which two-thirds of the world's old people depend, tend to break down due to pressures of urbanization, industrialization and rapid socio-cultural mobility, the elderly people come to be at loss. As a result of all these factors, old-age systems are in serious financial trouble. However, the situation happens to be more acute in Asia.

\section{Challenges Emerging}

In traditional communities, work and organizational structure of family were inter - connected. Relations and contacts within age groups were close, and there was mutual dependence between the young and the elderly groups. Such close connections and exchange of functions between generations within the family network ensured the survival of elderly people where there were no other forms of guaranteed social support in old age. The type of network allowed the elderly to have enough authority and participate in family functions based on family division of labor. However, industrialization and the process of social change in both Asia and Europe have led to social differentiation of age groups with reference to economic functions, official retirement and other such conditions.

Currently, due to the modernization of societies in different educational, scientific and technical respects, the younger generations are capable of providing for themselves. Therefore, the older generations are left isolated and dependent on pensions and other kinds of social help. This process eventually promotes relative independence of generations from each other, diminishes the necessity for cooperation and results in the destruction of family solidarity and mutual dependence. Therefore, in modern societies, responsibility for the elderly is more and more becoming formal and depersonalized. Under such network, the elderly people do not play their former roles. They depart from the family, i.e. not carrying out the role of the grandparents, and the younger generations tend to less require the support of the elderly [5].

\section{Socio - Economic Effects of Aging}

The inevitable harmful social and economic effects of aging is becoming obvious more than ever before with special reference to Asia. Most prominent among the concerns that are being voiced with respect to aging is how to fund social security programs in the face of increasing numbers of retired persons, and how to pay for rising health care costs generated by the elderly people [6]. These concerns have at times, led to the conclusion that population aging is bound to be more a catastrophic drain on economic resources. Actually speaking, while the Western (European) countries are and will continue to be rather well equipped to handle the present and projected increase in the older population, yet the emergence of the elderly social problems is something more recent. The whole scenario is more problematic for Asian countries rather than the Western European ones, wherein there are shortages of necessary infrastructures, and the societies that are rapidly changing to new cultural forms. Thus, the Asian elderly are much more socially and economically insecure in different dimensions.

Living in a demographically diverse world, has also led to unprecedented aging change too. While the global population increased by 2 billion during the last quarter of the $20^{\text {th }}$ century; reaching 6 billion in 2000, resources have not increased that much to respond the increasing elderly with special reference to Asia. As projected, the population will increase by another 2 billion during the first decades of the $21^{\text {st }}$ century, and as nearly all the increase has been, and will be in the developing countries including Asia, aging problems will emerge more than ever before in the region.

We, as living in a world of unprecedented demographic diversity, should be more cautious, and planning-minded. As the traditional demographic groupings of countries are breaking down, more 
socio-economic problems of the aging populations are emerging. Over the next 25 years, increases in population in South Asian and the Middle East are expected to be larger than the past quarter of the century. In contrast, in European countries, and in East Asia, population growth has slowed or stopped, and rapid population aging has become a serious concern [7]. Increasing levels of aging accompanied by increasing mobility and urbanization, are affecting economic and social outlooks of many countries.

The challenges found due to such diversities require adequate responses. The most urgent of these, occur where rapid population growth, high levels of poverty, and low level of economic growth coincide. Under such conditions the elderly face various problems.

\section{The Elderly Vulnerability}

Deteriorating environmental conditions and extreme events do not affect all countries and populations in the same way. Hence, many factors contribute to their vulnerability including poverty, poor health, low levels of education, gender inequality, lack of access to resources and services, and unfavourable geographical locations. All these, somehow or the other affect the elderly people more in Asia rather than the West. Under the conditions wherein the populations in general are socially disadvantaged or lack political voice, the elderly people in particular are also at greater risk. Vulnerable aging populations include the poorest, the least empowered segments and especially the women. These vulnerable aging persons have limited capacity to protect themselves from current and future environmental and social hazards, such as polluted air and water, catastrophes, and the adverse consequences of large-scale environmental change such as biodiversity loss, climate change etc.

To ease and solve the problems of the elderly people especially in Asian context, more interdisciplinary research and education addressing the above topics is necessary at all levels. The different disciplines should also conduct their studies in ways that make the result mutually accessible to the elderly.

\section{The Older Widows}

The aged members, especially old women face a serious situation in today's family structure. The demographic scenario of aging indicates a rise in the longevity of women [8]. As the proportion of the elderly people increases in the society, the increasing proportion of widows and widowers too, is very likely to emerge. Comparing the proportion of widows with the widowers, the number of the former is higher due to the fact that women marry earlier than men, and also they tend to outlive men. Similarly, after the ages of 60 , women have the chance of longer life. The chance of remarriage for men in their later life keeps the proportion of widowers lower than the widows almost everywhere. However, the consequences of widowhood leading to isolation and loneliness are more faced by the women rather than men.

Research shows that widowhood appears as an effect of marital dissolution worldwide. Apart from divorce, it in most cases happens as a natural event due to the death of a spouse. In both cases, women tend to suffer longer term of negative social and economic consequences, while men do not [9]

In spite of recognizing the problems faced by the elderly widows in many parts of Asia, governments are not ready to take more responsibility, but want the individual family to help its members in a crisis situation such as widowhood. The challenges faced by the widows towards the end of the $20^{\text {th }}$ century, have aggravated even today among large number of widows. To solve and improve the problem, assistance, cooperation and contributions of different institutions are required.

\section{Theoretical Context of Aging}

Aging as a transition in life course is fundamentally different from other ascribed statuses, such as race and gender. Being black or white, male or female and the like is a lifelong status, except in rare cases. Age, in contrast, is a transitional status because people periodically move from one age category to another. This process of a person moving through the life course from birth to death is called aging.

As people age, they face different sets of expectations and responsibilities, enjoy different rights and opportunities, and possess different amounts of power and control. Consequently, transitions from one age status to another are societally important [10]. They are often marked by rites of passage, and public ceremonies, i.e. full of ritual symbolism that record the transition being made. Weddings, retirement dinners, funerals etc. are all examples of rites of passage in an industrial society. It is somehow or the other different in different societies.

To better understand aging process, the five key sociological concepts will be helpful as we explore further the ideas of age, aging, and age structure with Asian and European connotations. Age structure is a specific element of the social structure of all human societies. That helps a society in allocating its resources.

Also, historical or cultural differences in age structure create different contexts for social action by individuals and groups. Changes in age structure also bring about problems of functional integration. Different proportions of age groups in a population affect power too, such as age for voting etc. Discussion of the meanings of age connotation in different societies is different from one culture to another.

Generally speaking, age shapes the flow of people into and out of social roles and statuses (social networks), and the rights and responsibilities that go with them, which is different from one society to another. Age also organizes the distribution of valued resources in a society such as money, power and prestige [11].

From the point of view of conflict theory, old people became a social problem when those in power in industrial world found it advantageous to push them aside. As the industrial revolution spread out more than a hundred years ago, managers of big businesses found old people as nuisance. At that time, they drew more wages than young workers who wanted the jobs of older workers. As older workers were pushed out of their jobs, the percentage of those over 
60 who worked declined steadily. As the aged lost out to younger groups with new technical and institutional resources, the meaning of: to retire changed from "to withdraw from public notice" to "to be no longer qualified for active service" [12]. To be old come to mean to be cast away; that is, to have almost nothing, and to be dependent on whatever someone might give you (in those day).

Conflict theory also explains how older people reacted to the social changes that brought them poverty and deprivation. They consolidated into a powerful lobbying force for social security. Therefore, the social security benefits currently available for the aging population, is the result of direct conflict between competing interest groups. The old banded together to push their interests and concerns, and that was a starting point for the aging benefits in the West.

The conflict perspective emphasizes that power, privilege and other resources are limited, and that they are distributed unequally among the various groups in the society. As it purses its own interests and values, each group comes in conflict with the others. Thus, say conflict theorists, whenever you examine a social problem, you should look at the distribution of power and privilege, for social problems center around the conflicting interests and values of a society's groups [13].

Conflict in society, then, is both natural and inevitable. Though it always exists, yet, it played highly a vital role to provide the elderly with retirement security, especially in the West in early 20th century. Therefore, the poor and neglected elderly could reach their rights with the framework of conflict theory.

\section{Asian Outlook}

In Asia, aging has become an issue of concern for the different sectors of governments dealing with the socio-economic needs of the elderly people. Though older people are expected to be respected, yet many societies are witnessing a new trend. Because of rural- urban migration, industrialization and shifting employment patterns among the younger adult population, older persons are facing increased social isolation and many other challenges in many Asian regions, particularly in rural areas. From a sociopsychological point of view, these isolated people in a community such as a large city feel alienated [14].

However, in some countries such as Thailand, the elderly people are valued for their contribution to society and are encouraged to remain active [15]. In addition to many other roles played by the seniors, most of the older persons in Thailand play a leading role in religious observances by supervising and providing information concerning religious activities to younger members of the family and community. They also transmit their traditions and culture to the younger generations.

Though the developing Asian countries have been experiencing rapid social, cultural and economic changes, yet the conditions of the elderly have not improved and changed in a satisfactory manner. So far as the elderly women are concerned, they are in a worse situation. They are identified as subordinates to men throughout their lives, and when they are ultimately left alone when get old, they are deeply poor and destitute. While in the developed countries retirement is expected to be the period to enjoy personal and leisure activities, in the developing Asian countries, the elderly are still preoccupied with their basic livelihood. As social welfare and health insurance in many developing Asian countries have limited resources, the individual financial resources play a significant role to enhance and improve one's quality of life [16]. Under such a scenario, the elderly in developing Asia financially remain dependent on others. To illustrate it more thoroughly, they psychologically and physically depend more on others rather than the state, or the relevant agencies.

Very few of Asian countries have infrastructures enough to help their unable and the elderly people. One of the countries well functioning in the course is known to be Singapore - wherein the strong financial resources have helped the aging population, and thereby enhanced their quality of life in different ways. Modernization in many parts of Asia has greatly influenced the lives of the elderly due to increasing change in the family structure and ties, more mobility among the families, more employment by the women etc. All these have caused the families to be more segmented, and consequently not to have time enough to invest in the elderly people. Also, with the increasing decline in fertility and mortality rates, population aging is appearing more than ever before: generating significant demands for long-term care [16]. Hence, the demographic trends are dramatically changing the face of many nations in Asia, or will soon do so in the future. One way of measuring the speed of these shifts is through a measure of "population aging". Although the phenomenon is very recent in Asia, but it is rapidly spreading in many parts of the continent.

However, as explored, still majority of the elderly wish to live with their adult children. There is clear evidence showing the familism and family-feeling among the elderly in most parts of Asia. As observed, modernization is seen a paradoxical phenomenon in Asia since it is eroding the traditional support system.

However, today the elderly people have come into the agenda of many Asian countries as it happened in the West previously. Similarly, Asia too needs to develop enough literature on the topic. It is becoming the region where the majority of the elderly people are concentrated. That is to say, the majority (52\%) of the world's senior citizens (people 60 and over) live in Asia; four in every fifteen are concentrated in Eastern Asia including China, and one in six inhabit South-central Asia including India [17]. Similarly, about one in fifteen live in South-east Asia including Indonesia, and Western Asia includes the rest.

Such development is largely due to economic success in the region, and a result of success in population control since early 1980s. Increased life expectancy which also resulted in, or is a consequence of improved health care and living standards, has led to increasing old age in all societies, but more in the Western world. However, while until around the 1970s many countries especially in South-east Asia were still considered to have young populations, since 1980s the older age categories have increased; 
making it necessary to examine the conditions of these growing elderly people.

It is noted that since 1950s, life expectancy of men has increased by 20 years or more in Indonesia, Republic of Korea and Thailand and by 15 years in Japan. While the number of women has even increased more dramatically [18], these developments have eventually resulted in an accelerated increase in the proportion of the elderly people in almost all parts of Asia, but with some fluctuations.

The elderly people's conditions are not the same all over Asia. For example, in the South-east Asia, the proportion of those aged 60 and over is not yet as high as in Japan. There is growing concern in this regard since the necessary institutional arrangements for taking care of them outside the family are not yet in place. Therefore, much has to be done to bring it in order and adequacy (Table 1).

Table 1: Comparative Aging Indicators of Asia and Europe in Selected Countries in Three Periods (\%).Source(s): World Population Data Sheet(s) 1995, 2005 and 2015.

\begin{tabular}{|c|c|c|c|c|c|c|c|}
\hline \multicolumn{4}{|c|}{ Asia } & \multicolumn{4}{|c|}{ Europe } \\
\hline \multirow{2}{*}{$\begin{array}{c}\text { (Region) } \\
\text { Country }\end{array}$} & \multicolumn{3}{|c|}{ Percent $65^{+}$} & \multirow{2}{*}{$\begin{array}{l}\text { (Region) } \\
\text { Country }\end{array}$} & \multicolumn{3}{|c|}{ Percent $65^{+}$} \\
\hline & 1995 & 2005 & 2015 & & 1995 & 2005 & 2015 \\
\hline Asia & 5 & 6 & 8 & Europe & 13 & 16 & 17 \\
\hline Armenia & 7 & 11 & 11 & Denmark & 15 & 15 & 19 \\
\hline Azerbaijan & 5 & 7 & 6 & Finland & 14 & 16 & 20 \\
\hline Iraq & 3 & 3 & 3 & Ireland & 11 & 11 & 13 \\
\hline Jordan & 3 & 3 & 3 & Norway & 16 & 15 & 16 \\
\hline Lebanon & 5 & 6 & 7 & Sweden & 18 & 17 & 20 \\
\hline Saudi Arabia & 2 & 3 & 3 & Britain & 16 & 16 & 17 \\
\hline Turkey & 4 & 6 & 8 & Austria & 15 & 15 & 18 \\
\hline India & 3 & 2 & 6 & Belgium & 16 & 17 & 18 \\
\hline Iran & 4 & 4 & 8 & France & 15 & 16 & 18 \\
\hline Nepal & 3 & 4 & 6 & Germany & 15 & 18 & 21 \\
\hline Pakistan & 3 & 4 & 4 & Luxenbourg & 13 & 14 & 14 \\
\hline Sri Lanka & 4 & 6 & 8 & Holland & 13 & 14 & 18 \\
\hline Indonesia & 4 & 5 & 5 & Switzerland & 15 & 16 & 18 \\
\hline Singapore & 7 & 8 & 12 & Czech Rep. & 10 & 14 & 18 \\
\hline Thailand & 4 & 7 & 11 & Hungary & 14 & 16 & 18 \\
\hline Viet Nam & 5 & 7 & 7 & Poland & 11 & 13 & 16 \\
\hline China & 6 & 8 & 10 & Romania & 11 & 14 & 15 \\
\hline Japan & 14 & 20 & 27 & Russia & 11 & 13 & 14 \\
\hline Korea, North & 4 & 8 & 10 & Italy & 16 & 19 & 22 \\
\hline Korea, South & 5 & 9 & 14 & Portugal & 15 & 17 & 20 \\
\hline Taiwan & 7 & 9 & 13 & Spain & 14 & 17 & 18 \\
\hline
\end{tabular}

\section{European Outlook of Aging}

The establishment of individual and universal mandatory pension rights has come to be known as an efficient way to eradicate poverty in old age among both women and men. Health promotion and well-being of these people in Europe are among the issues which have been of priority and well attended in Europe as compared with Asia in the course of the twentieth century.

Sociologically speaking, the discipline of sociology came into being to explore and solve, inter alia, the emerging challenges and the social issues of the elderly People, and thereby to enhance their quality of life. A major task of sociology being to analyze the social problems, gradually social welfare enhanced first in Europe leading to social order which included the elderly welfare too.
"Modernization" which first occurred in Europe, was a multidimensional concept. It was divided into four distinct elements:

1) Economic modernization (industrialization),

2) Political modernization (democratization),

3) Societal modernization (realization of freedom and equality) and

4) Cultural modernization (the move towards rationalism).

All these four dimensions affected the elderly lives somehow or the other. The process of modernization still advancing is changing the lives of the elderly in almost all the European countries, namely, changing their quality of life. 
Progress in general quality of life has contributed to the major "social risks" such as illness, accidents and impecunious old age to be protected in Europe on larger scale as compared with Asia. At the same time, while poverty is lower among the elderly people in Europe as compared with Asia, yet social exclusion is appearing in the continent as a new concept. Poverty and social exclusion being central issues of social policy, so far as the elderly are concerned, they have been well addressed in Europe. It could be illustrated as follows: (Figure 1).

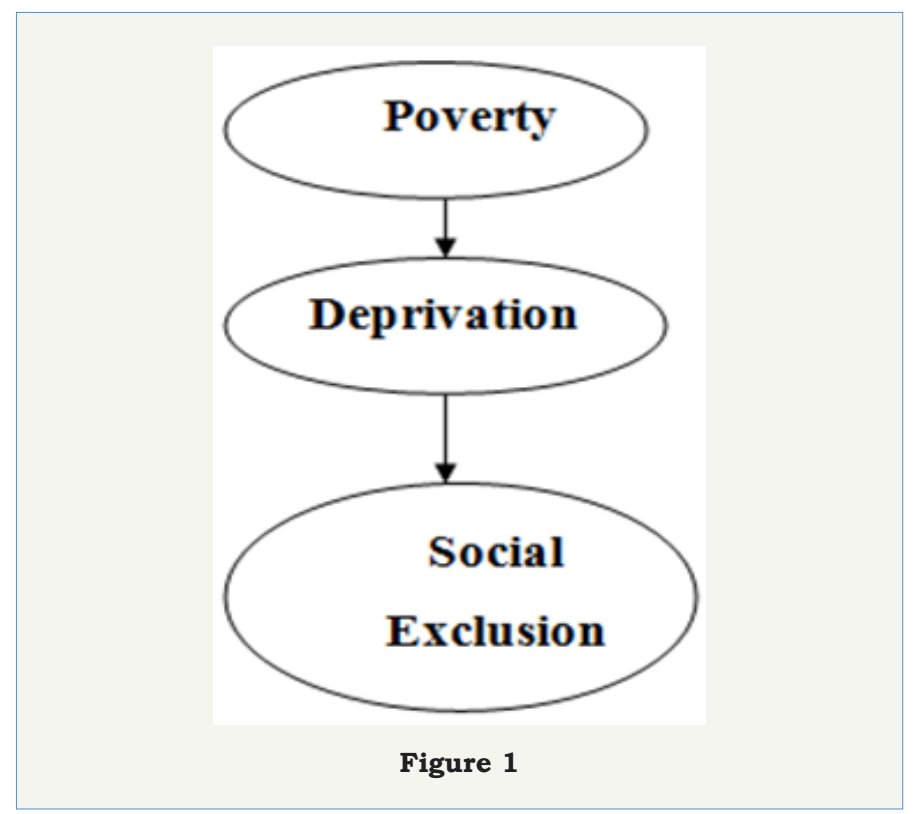

Since new forms of administration occurred in Europe much earlier than Asia due to the emergence of industrialization, elderly issues, and the methods to eliminate them started earlier in that continent, especially in the Western part as compared with Asia, and that is why the quality of life there, started to be enhanced earlier too.

Some of the quality- of- life indicators as found [15], could be outlined as follows:
a) Life expectancy,
b) Availability of health care services,
c) Affordability of health care,
d) Quality of health care,
e) Quality of health control,
f) Quality of housing,
g) Affordability of housing.

Comparative sociological research indicates that there are meaningful differences between the above indicators in Asia and Europe so far as the elderly are concerned. The main causes of difference between the two stems from lack of resources, lack of capital, underdevelopment of administration etc.

\section{Conclusion}

There is a clear need for research on the type and magnitude of the conditions and problems of older persons in relation to gender, age groups, physical and mental health status, socio- economic status, and ability to continue to be productive. Research is also necessary on the enabling environment, the resources available in the family, community, society, and the state to care for older persons in a way that is conductive to making them independent, self- reliant and productive.

So far as older women are concerned, they particularly face greater risk of physical and psychological abuse due to discriminatory and societal attitudes, and the non-realization of the human rights of women. Women's poverty is directly related to the absence of economic opportunities and autonomy, lack of access to economic resources including credit, land ownership, and inheritance, lack of access to education and support services and minimal participation in the decision-making process. Poverty can also force women into a situation in which they are vulnerable to sexual exploitation $[19,20]$.

It is quite evident that the unprecedented demographic, social and economic changes which had their origins in the nineteenth and the twentieth centuries, and are well continuing into the 21st century, are transforming the world in different dimensions including the elderly. The declines in fertility reinforced by increasing longevity have produced and will continue to produce unprecedented changes in the structure of all societies, notably the historic reversal in the proportions of the young and the old persons in Europe, and in some cases in Asia [21,22]. Many parts of Asia are still in their infancy with respect to the development of formal services. Hence, despite rapid social change, family care giving for the elderly is still the dominant type of care giving in Asia. Likewise, the profound, pervasive and enduring consequences of population aging presents enormous opportunities as well as enormous challenges for all societies. That is, a scenario which ever needs research, development, planning and investment [23].

\section{References}

1. Population Newsletter (2001) UN Population Division. Department of Economic and Social Affairs, New York, USA.

2. Tinker $H$ (1983) Improving the quality of life and promoting independence of elderly people. HMSO, London.

3. Hughes B (1990) Quality of Life in Peace S, Researching Social Gerontology. Sage, pp. 46-58.

4. (1995) Finance and Development. IMF Publications, Washington DC, USA.

5. Aleksandrova MD (1974) Problems of social and psychological gerontology. University of Leningrad Press, Leningrad, Russia.

6. Mullan P (2000) The imaginary time bomb: why aging problem is social problem? I. B. Tauris Publishers, New York, USA.

7. Population and Development Review (2002) Population Council 28(4): 599-820.

8. Desai N, Thakkar U (2003) Women in Indian society. National Book Trust, New Delhi, India, pp. 85. 
9. Neubeck KJ (1996) Sociology. McGraw-Hill Inc, New York, USA, pp-478.

10. Keller S (1994) Sociology, McGraw-Hill, London.

11. O'Rand AM, Margaret LK (1990) Concepts of the Life Cycle. Annual Review of Sociology 16: 241-262.

12. Achenbaum WA (1978) Oldage in the New Land: The American experience since 1970. Johns Hopkins University Press, Baltimore, Maryland, USA.

13. Henslin JS (1983) Social problems. McGraw- Hill, London.

14. A Team of Experts (2000) Advanced Learner's Dictionary of Sociology. Anmol Publications, New Delhi, India.

15. UNFPA (2002) Population Aging and Development. New York, USA.

16. International Federation on Aging (IFA) (2001) Montreal conference selected papers, Montreal, Canada.

Creative Commons Attribution 4.0

International License

For possible submission use the below is the URL Submit Article
17. Conception MB (1996) The graying of Asia: demographic dimensions in: added years of life in Asia, current situation and future challenges. ESCAP, Bangkok, Thailand.

18. Human Development Report (1997) Oxford University Press, New York, USA.

19. MIRE (1997) Comparing social welfare systems in southern Europe, Volume 3. Florence Conference, Italy.

20. Gruyter W (1993) European sociology. ISA Publications, New York, USA. 21. Population and Development Review (2001) Population Council 27(1).

22. Valencia Forum (2002) International association of gerontology. Cosponsored by UNFPA, Mardrid International Plan of Action on Aging.

23. World population data sheet (s) 1995, 2005 and 2015, Population Reference Bureau, Washington DC, USA.

\section{Your subsequent submission with Crimson Publishers will attain the below benefits}

- High-level peer review and editorial services

- Freely accessible online immediately upon publication

- Authors retain the copyright to their work

- Licensing it under a Creative Commons license

- Visibility through different online platforms

- Global attainment for your research

- Article availability in different formats (Pdf, E-pub, Full Text)

- Endless customer service

- Reasonable Membership services

- Reprints availability upon request

- One step article tracking system 